BMJ Open Ophthalmology

\title{
Functional benefits of a chorioretinal anastomosis at 2 years in eyes with a central retinal vein occlusion treated with ranibizumab compared with ranibizumab monotherapy
}

\author{
Ian L McAllister (D , , ${ }^{1}$ Lynne A Smithies, ${ }^{1}$ Fred K Chen, ${ }^{1,2}$ David A Mackey, ${ }^{1}$ \\ Paul G Sanfilippo ${ }^{3}$
}

To cite: McAllister IL, Smithies LA, Chen FK, et al. Functional benefits of a chorioretinal anastomosis at 2 years in eyes with a central retinal vein occlusion treated with ranibizumab compared with ranibizumab monotherapy. BMJ Open Ophthalmology 2021;6:e000728. doi:10.1136/ bmjophth-2021-000728

- Additional material is published online only. To view, please visit the journal online (http://dx.doi.org/10.1136/ bmjophth-2021-000728).

Received 24 January 2021 Revised 22 February 2021 Accepted 22 February 2021

Check for updates

(C) Author(s) (or their employer(s)) 2021. Re-use permitted under CC BY-NC. No commercial re-use. See rights and permissions. Published by BMJ.

${ }^{1}$ Lions Eye Institute (Centre for Ophthalmology and Visual Science), University of Western Australia, Perth, Western Australia, Australia ${ }^{2}$ Ophthalmology Department, Royal Perth Hospital, Perth, Western Australia, Australia ${ }^{3}$ Centre for Eye Research Australia, Melbourne, Victoria, Australia

Correspondence to Dr lan L McAllister; ianmcallister@lei.org.au

\section{ABSTRACT}

Objective To evaluate the functional benefits (best corrected visual acuity (BCVA), central subfield thickness, injection loads, central venous pressure (CVP)) of a laserinduced chorioretinal anastomosis (L-CRA) in patients with central retinal vein occlusion (CRVO) treated with ranibizumab compared with ranibizumab monotherapy. Methods and Analysis This is a post-hoc analysis of the 2-year randomised ranibizumab plus L-CRA for CRVO trial. Twenty-four patients (82.5\%) developed a functioning or successful L-CRA; outcome effects were monitored in the monthly as-needed ranibizumab phase from months 7 to 24 and compared with the ranibizumab monotherapy group $(\mathrm{n}=29)$.

Results From months 7 to 24 , the mean $(95 \% \mathrm{Cl})$ injection load for the functioning L-CRA group was 2.18 (1.57 to 2.78) compared with 7.07 (6.08 to 8.06) for the control group $(p<0.0001)$. The mean BCVA was averaged across all timepoints between the control and functioning L-CRA groups (average difference $=11.46$ (3.16 to 19.75) letters, $p=0.01$ ). At 2 years, there was an $82.5 \%$ reduction in the odds of high CVP (greater or equal to central retinal artery diastolic pressure) for those with a successful L-CRA compared with controls $(p<0.0001)$.

Conclusion For patients with CRVO, adding L-CRA as a causal-based treatment to conventional therapy reduced CVP and injection loads and offered improved BCVA.

Trial registration number ACTRN12612000004864.

\section{INTRODUCTION}

The treatment outcomes for central retinal vein occlusion (CRVO) have dramatically improved following the advent of intravitreal administration of vascular endothelial growth factor (VEGF) antagonists. ${ }^{1-4}$ While this approach delivers significant benefits in terms of improving best corrected visual acuity (BCVA), these agents impose a considerable burden to both the patients and the health services. The treatments may be required for years at considerable financial, time and resource cost to both the patient

\section{Key messages}

What is already known about this subject?

While the current treatments for central retinal vein occlusion (CRVO) with vascular endothelial growth factor inhibitors represent a major advance in visual outcomes, they fail to address the underlying causal pathology, which is an obstruction to venous outflow, and also involve a considerable burden of therapy for patients and health services.

\section{What are the new findings?}

- The creation of a laser-induced chorioretinal anastomosis by providing a bypass to this obstruction addresses causal pathology and reduces central venous pressure (CVP), which up until the current time has remained an unaddressed component of macular oedema, and improves both visual outcomes and treatment burden.

\section{How might these results change the focus of research or clinical practice? \\ - Treatments to reduce CVP and obstruction to venous outflow in CRVO can improve outcomes, and further research into how this can be achieved safely and reliably is warranted.}

and the health authority. ${ }^{56}$ These agents address only the component of the CRVOinduced macular oedema secondary to the upregulated VEGF, without having any effect on the underlying causal pathology, which is an obstruction to venous outflow. We have previously reported the 2-year results of a randomised clinical trial (RCT) comparing visual outcomes and injection loads in patients with CRVO treated with either ranibizumab monotherapy or ranibizumab combined with a laser-induced chorioretinal anastomosis (L-CRA). ${ }^{7}$ Compared with the monotherapy group, the overall combination group, which included both those with a 
successful development of an L-CRA $(82.5 \%)$ and those that were unsuccessful, showed significantly lower injection loads, greater reduction in central subfield thickness (CST) and improved BCVA. As it appears to be beneficial to address the obstruction to venous outflow by an L-CRA as a causal-based treatment, in addition to conventional VEGF blockade, this post-hoc analysis investigates the association between central venous pressure (CVP), CST, injection load and BCVA in those in the group with a successful or functioning anastomosis $(82.8 \%$ of the total combination group) versus those treated with ranibizumab monotherapy alone. This may illustrate what potential additional outcome benefits may be achieved where both the obstruction to venous outflow as well as the cytokine dysregulation have been addressed in CRVO.

\section{MATERIALS AND METHODS}

A randomised, 24-month study was conducted at the Lions Eye Institute, Perth, Western Australia, comparing the efficacy of combining L-CRA with intravitreal ranibizumab versus ranibizumab alone (control) for patients with macular oedema secondary to CRVO. ${ }^{7}$ Entry criteria, treatment schedules and retreatment criteria were based on the CRUISE study. ${ }^{1}$ All patients were randomised to either an L-CRA ${ }^{89}$ or sham procedure at baseline (month 0 ), with monthly ranibizumab $0.5 \mathrm{mg}$ injections as per the CRUISE study, then commencing for 6 months (months $1-7)$ from month 1 before entering the monthly maintenance pro re nata (PRN) phase from months 7 to 24 . As there is some evidence that the development of an L-CRA is VEGF-dependent, ${ }^{8}$ intravitreal VEGF therapy was not initiated until 1 month after the L-CRA attempt. For the remaining duration of the study (months 7-24, maintenance phase), participants continued to be evaluated monthly and received intravitreal ranibizumab if they met the following criteria: (1) $>50 \mu \mathrm{m}$ increase in CST on spectral domain optical coherence tomography (SD-OCT) compared with the lowest previous measurement; (2) new or persistent cystic retinal changes, subretinal fluid or persistent diffuse oedema $\geq 270 \mu \mathrm{m}$ in CST; and (3) loss of five or more letters on the Early Treatment Diabetic Retinopathy Study (ETDRS) chart from the previous best measurement in conjunction with any increase in CST. The primary efficacy outcome was the number of injections required during the maintenance PRN phase from months 7 to 24. Predetermined secondary outcomes were changes in BCVA, CST and CVP.

Mixed-effects model regression models were used to examine treatment effects and other covariates on injection numbers, BCVA and CST over time as per our previous publication. ${ }^{7}$

All participants provided written informed consent. The trial protocol can be found in the online supplemental material.

Patients or the public were not involved in the design, or conduct, or reporting or dissemination plans of our research. The trial was registered with the Australian New Zealand Clinical Trials Registry.

\section{RESULTS}

Fifty-eight patients were enrolled into the original study, were randomised to either ranibizumab monotherapy (control) or a combination of ranibizumab with L-CRA and were included in this post-hoc analysis. Patients were 18 years or older with a treatment-naïve CRVO of $<9$ months duration, BCVA of 73 to 24 ETDRS letter score (Snellen equivalent $6 / 12$ to $6 / 96$ ), and CST greater or equal to $250 \mu \mathrm{m}$ on SD-OCT. Twenty-nine patients were enrolled into each group and their baseline characteristics were comparable. ${ }^{7}$ A functioning L-CRA (figures 1 and 2) was created in at least one site in 24 of $29(82.8 \%)$ patients randomised to the combination group (15 patients with two sites and 9 patients with one site), with the remaining 5 unsuccessful.

\section{Injection load}

The functioning L-CRA group required significantly less ranibizumab compared with the control group during the overall monthly PRN period from 7 to 24 months, with a mean $(95 \% \mathrm{CI})$ of 2.18 (1.57 to 2.78$)$ injections compared with 7.07 (6.08 to 8.06) ( $\mathrm{p}<0.0001)$. For the second year (13-24 months), this reduced further to a mean of 0.94 (0.62 to 1.42) compared with 4.61 (3.87 to 5.47$)(\mathrm{p}<0.0001)$, respectively. Following the final mandatory intravitreal ranibizumab at month 7,10 patients in the functioning L-CRA group compared with 1 patient in the control group did not require any further injections $(p=0.007)$ for the remainder of the study. The non-functioning L-CRA group had similar injection loads to the control $(\mathrm{p}=0.61)$ (table 1$)$.

\section{Best corrected visual acuity}

Mixed-effects model regression analysis adjusting for baseline (month 0) variations in BCVA, CST, age and CRVO duration was performed to examine changes in BCVA over time. To compare BCVA in the control versus combination groups, timepoint comparisons (months 7, 13 and 24) were made against the month 1 data, which was when both groups commenced mandatory monthly ranibizumab for 6 months as per the CRUISE study. ${ }^{17}$ While there was no significant difference in BCVA at baseline between all groups, there was some improvement comparatively in the group with the functioning L-CRA at month $1 .^{7}$ The mean BCVA $(95 \%$ CI) (ETDRS letters) at baseline (month 0) was 54.6 (50.1 to 59.1) for the control group and 60.3 (55.3 to 65.4) for the functioning L-CRA group. At the month 1 timepoint (ranibizumab commenced) there was a decrease to 45.3 (39.0 to 51.6) and 56.8 (49.7 to 63.9 ). These then improved to 61.5 (55.2 to 67.8 ) and 73.0 (65.8 to 80.1) at 7 months, 61.7 (55.4 to 68.0$)$ and 73.1 (66.0 to 80.3$)$ at 13 months, and 61.3 (55.0 to 67.6) and 72.8 (65.6 to 79.9) at 24 months, respectively. There was a statistically significant difference in mean BCVA (95\% CI) (ETDRS letters) 

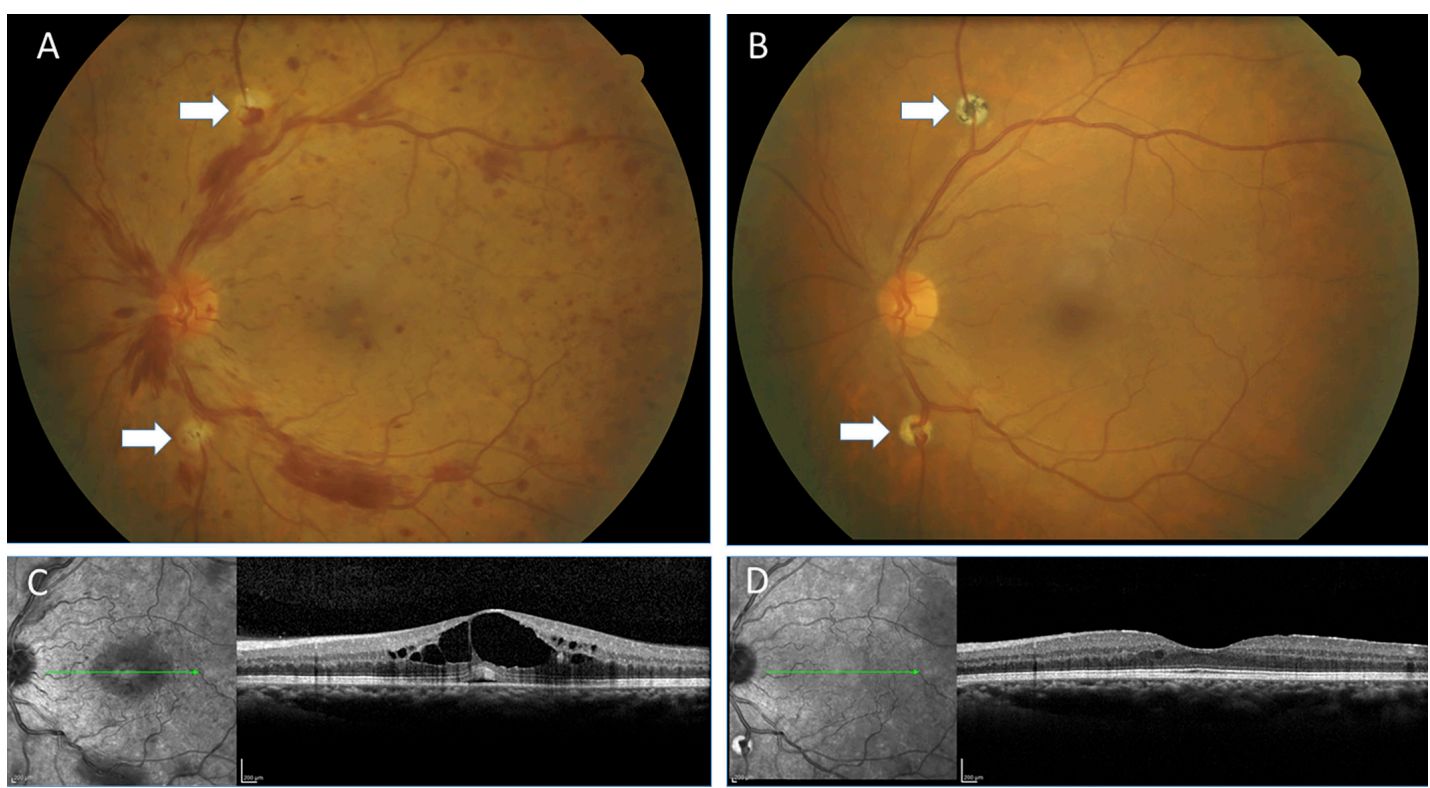

Figure 1 (A) CRVO at presentation. BCVA is 6/18. Two anastomosis attempts have been made above and below the disc (arrows). There is a small amount of haemorrhage from each as the side wall of the vein has been breached. (B) At 24 months. The superior anastomosis has not formed; however, the inferior one (arrows) shows a well-developed L-CRA. The patient's vision has returned to $6 / 5$ and no injections of ranibizumab were required during the PRN follow-up phase of the study. (C) OCT at baseline showing significant macular oedema. (D) OCT at 24 months showing resolved macular oedema. BCVA, best corrected visual acuity; CRVO, central retinal vein occlusion; L-CRA, laser-induced chorioretinal anastomosis; OCT, optical coherence tomography; PRN, pro re nata.

averaged across all timepoints between the control and functioning L-CRA groups (average difference $=11.46$ (3.16 to 19.75 ) letters, $\mathrm{p}=0.01$ ). There was no difference between the control and non-functioning L-CRA groups (average difference $=-3.64 \quad(-18.00$ to 10.73$)$ letters, $\mathrm{p}=0.64$ ) (figure 3).

\section{Central subfield thickness}

Baseline CSTs were well matched at baseline, with no significant difference in CST in the two treatment groups compared with the control group. Between baseline and month 1 (ranibizumab commenced), there was a mean (95\% CI) CST reduction for the functioning L-CRA group of $208 \mu \mathrm{m}$ ( -314 to -102$)$ compared with the control group ( $p=<0.0001)$, presumably due to the effects of the developing L-CRA. From month 1, the changes in CST remained stable, with no significant difference between the control group and the group with a functioning $(\mathrm{p}=0.15)$ or a non-functioning L-CRA $(\mathrm{p}=0.35) \quad$ (table 2$)$.

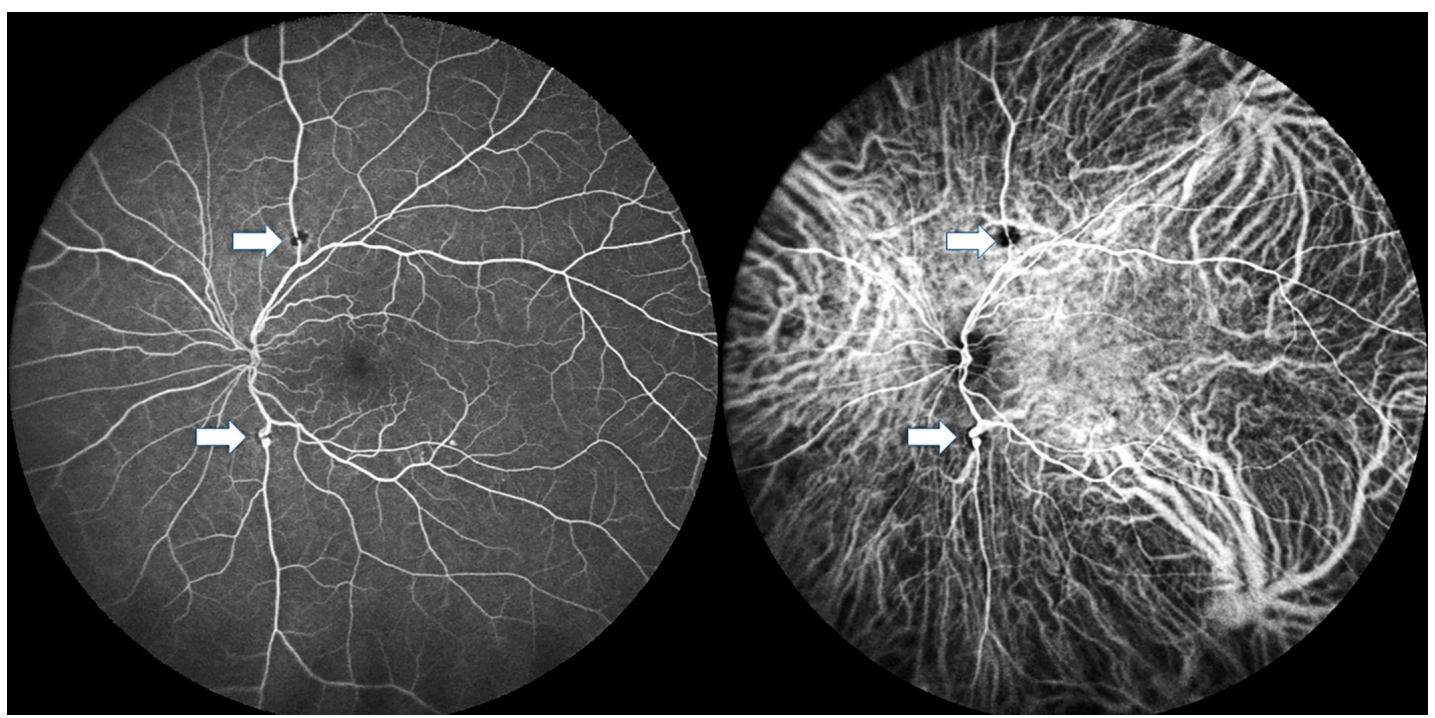

Figure 2 Combined fluorescein and indocyanine angiogram of the patient in figure 1 at 24 months. The sites of the L-CRA attempts are marked with arrows. The superior one does not appear to be draining into the choroid; however, the inferior one shows a large draining choroidal vein. L-CRA, laser-induced chorioretinal anastomosis. 
Table 1 Estimated $(95 \% \mathrm{Cl})$ injection loads over various time intervals*

\begin{tabular}{|c|c|c|c|c|}
\hline & Months 1-6 & Months 7-12 & Months 13-24 & Months 7-24 \\
\hline Control & 5.78 (4.97 to 6.73$)$ & 2.46 (1.95 to 3.12$)$ & 4.61 (3.87 to 5.47 ) & 7.07 (6.08 to 8.06$)$ \\
\hline Functioning L-CRA & 5.52 (4.63 to 6.57$)$ & 1.24 (0.86 to 1.79$)$ & 0.94 (0.62 to 1.42$)$ & 2.18 (1.57 to 2.78$)$ \\
\hline $\begin{array}{l}\text { Count ratio compareding } \\
\text { with to control }\end{array}$ & & $0.50(0.33$, to --0.78$)$ & $0.20(0.13$, to 0.32$)$ & $0.32(0.23$, to 0.44$)$ \\
\hline$P$ value & & 0.002 & $<0.0001$ & $<0.0001$ \\
\hline Non-functioning L-CRA & $5.86(4.03$ to 8.54$)$ & 2.63 (1.51 to 4.56$)$ & 5.26 (3.54 to 7.84$)$ & $7.88(5.30$ to 10.47$)$ \\
\hline $\begin{array}{l}\text { Count ratio compareding } \\
\text { towith control }\end{array}$ & & $1.07(0.59$, to 1.94$)$ & $1.14(0.60$, to 0.55$)$ & $1.10(0.76$, to 1.60$)$ \\
\hline$P$ value & & 0.83 & 0.55 & 0.61 \\
\hline
\end{tabular}

*Based on regression analysis.

L-CRA, laser-induced chorioretinal anastomosis.

\section{Central venous pressure}

Assessments were done at each visit using methods previously described. ${ }^{10}$ The results were divided into two groups: the first ('low CVP') being CVP less than the central retinal arterial (CRA) diastolic pressure, where retinal blood flow was likely to be maintained throughout the cardiac cycle, and the second ('high CVP') equal to this or above. At baseline, only 1 patient of the total 58 in the study had a CVP less than the CRA diastolic pressure, whereas at the 24-month stage using last observation carried forward 6 control patients compared with 22 in the functioning L-CRA group had a CVP less than the CRA diastolic pressure. None of the non-functioning L-CRA group (5 of 29) had a final reduction in CVP to this level (figure 4). Using logistic regression, the OR for treatment suggests an $82.5 \%$ reduction in the odds of 'high CVP' for those who developed a successful L-CRA compared with controls $(\mathrm{p}<0.0001)$.

\section{DISCUSSION}

Current therapeutic interventions (anti-VEGF agents, steroids) for CRVO-associated macular oedema, while effective in the short term, address only the sequelae of the obstruction to venous outflow and do not modify underlying causative processes. The pathogenesis of this is probably multifactorial, with raised CVP, cytokine upregulation and inflammatory components all potentially playing a role. The elevated CVP, which can be considerable in CRVO, ${ }^{11}{ }^{12}$ has been previously investigated by us and found to be directly proportional to reductions in BCVA, amount of retinal ischaemia and anterior segment neovascularisation. ${ }^{10}$ To achieve maximal BCVA and stability of vision would require both the CVP and cytokine dysregulation to be addressed. The intravitreal half-life of a $0.5 \mathrm{mg}$ injection of ranibizumab is estimated to be 7.19 days, and while this dries out the macula, as seen by larger studies, its effect does wear

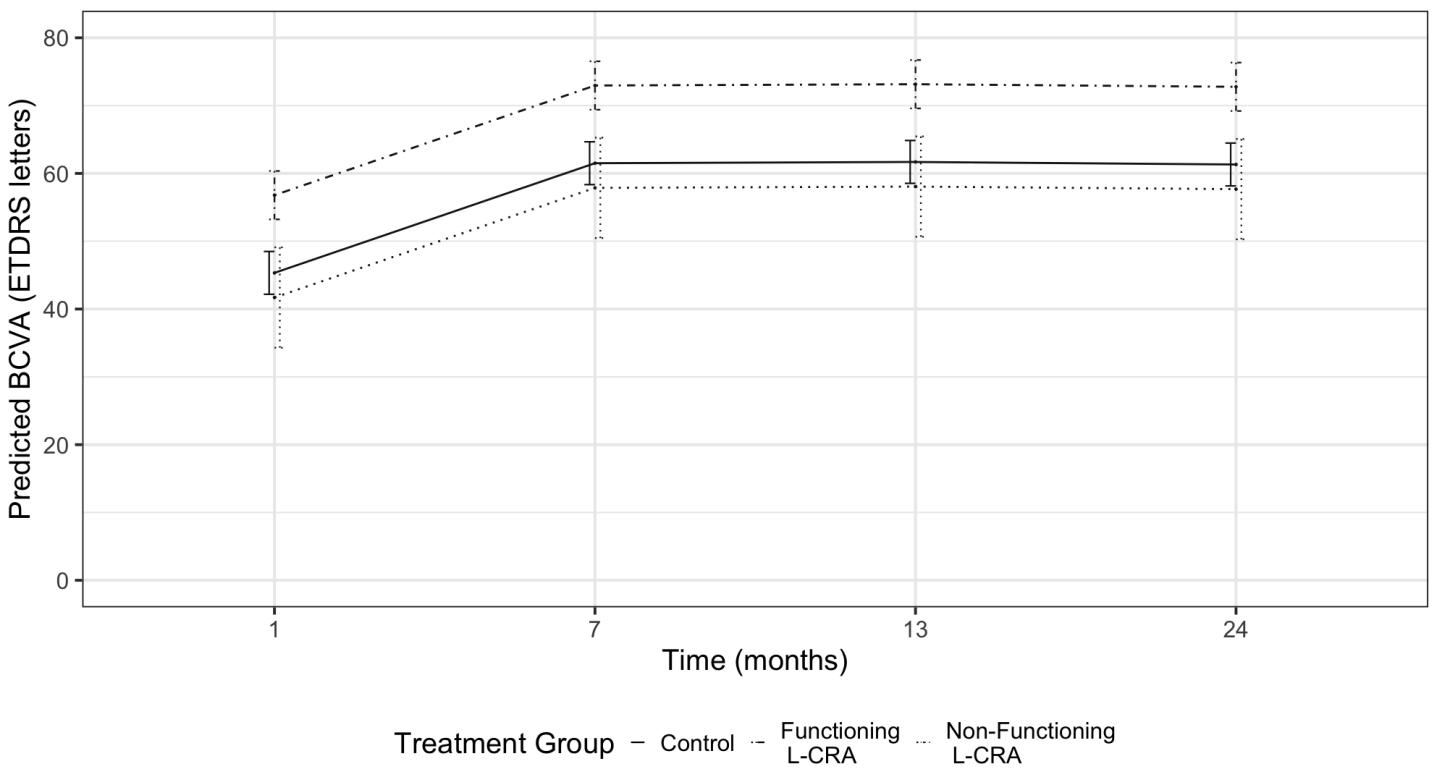

Figure 3 Predicted BCVA across time and treatment groups. These are control or ranibizumab monotherapy, non-functioning L-CRA and functioning L-CRA. Timepoint comparisons (months 7, 13 and 24) were made against the month 1 data, which was when all groups commenced mandatory monthly ranibizumab for 6 months. Vertical bars are \pm 1 SEM. BCVA, best corrected visual acuity; ETDRS, Early Treatment Diabetic Retinopathy Study; L-CRA, laser-induced chorioretinal anastomosis. 
Table 2 Central subfield thickness $(\mu \mathrm{m})$ at different timepoints

\begin{tabular}{|c|c|c|c|c|c|}
\hline & Month 0 & Month 1 & Month 7 & Month 13 & Month 24 \\
\hline \multicolumn{6}{|l|}{ Control } \\
\hline Baseline (mean) & 763.3 & & & & \\
\hline $95 \% \mathrm{Cl}$ & 687.4 to & & & & \\
\hline Change from month 1 & & & -493.9 & -470.7 & -494.6 \\
\hline $95 \% \mathrm{Cl}$ & & & -581.1 to -406.58 & -557.9 to -383.38 & -581.9 to -407.34 \\
\hline$P$ value & & & $<0.0001$ & $<0.0001$ & $<0.0001$ \\
\hline
\end{tabular}

\begin{tabular}{|c|c|c|c|c|c|}
\hline \multicolumn{6}{|l|}{ Functioning L-CRA } \\
\hline Baseline (mean) & 700.6 & & & & \\
\hline $95 \% \mathrm{Cl}$ & 637.9 to 763.3 & & & & \\
\hline$P$ value ${ }^{*}$ & 0.20 & & & & \\
\hline Change from month 1 & & & -340.9 & -325.5 & -365.1 \\
\hline $95 \% \mathrm{Cl}$ & & & -436.8 to -244.93 & -421.4 to -229.56 & -461.0 to -269.14 \\
\hline$P$ value & & & $<0.0001$ & $<0.0001$ & $<0.0001$ \\
\hline Difference cf control & & -208.0 & -55.0 & -62.8 & -78.5 \\
\hline $95 \% \mathrm{Cl}$ & & -314.4 to -101.56 & -161.5 to 51.42 & -169.3 to 43.59 & -184.9 to 27.97 \\
\hline$P$ value & & $<0.0001$ & 0.31 & 0.25 & 0.15 \\
\hline \multicolumn{6}{|l|}{ Non-functioning L-CRA } \\
\hline Baseline (mean) & 774.6 & & & & \\
\hline $95 \% \mathrm{Cl}$ & 605.7 to 943.5 & & & & \\
\hline$P$ value ${ }^{*}$ & 0.88 & & & & \\
\hline Change from month 1 & & & -602.8 & -574.2 & -388.4 \\
\hline $95 \% \mathrm{Cl}$ & & & -813.0 to -392.60 & -784.4 to -364.00 & -598.6 to -178.20 \\
\hline$P$ value & & & $<0.0001$ & $<0.0001$ & 0.0004 \\
\hline Difference cf control & & -17.9 & -126.8 & -121.4 & 88.3 \\
\hline $95 \% \mathrm{Cl}$ & & -203.6 to 167.85 & -312.5 to 58.91 & -307.1 to 64.31 & -97.4 to 274.07 \\
\hline$P$ value & & 0.85 & 0.18 & 0.20 & 0.35 \\
\hline
\end{tabular}

*Two-sample t-test for difference in means (sham+ranibizumab vs L-CRA+ranibizumab (functioning and non-functioning groups)).

cf, compared with; L-CRA, laser-induced chorioretinal anastomosis.

off. ${ }^{13}$ Elevated intraretinal VEGF downregulates capillary endothelial barrier proteins, and as the VEGF blockade wears off these again leak and this is likely to be exacerbated by the elevated CVP. ${ }^{14}{ }^{15}$ In this study, the CST remained very similar between the control and treatment subgroups once the ranibizumab was commenced at month 1, unlike the BCVA where there was a significant improvement in the group with a functioning L-CRA.

Timepoint comparisons for BCVA were made against the month 1 data (as in the previous study), when both groups commenced the mandatory monthly ranibizumab for 6 months. ${ }^{7}$ While baseline (month 0) BCVAs were comparable there was a reduction in BCVA for the control group by month 1 compared with the functional L-CRA group, presumably due to the effect of the developing anastomosis. This would tend to favour, for a comparison, the group with the lower level of BCVA due to the ceiling effect, as seen with other studies such as the CRYSTAL study, where those with lower baseline BCVA achieved higher mean letter score increases, as there was more room for improvement than in those with higher baseline BCVA. ${ }^{16}$ Despite this the functioning L-CRA group achieved a visual improvement of greater than two ETDRS chart lines compared with the control group over the 2 years of follow-up.

By reducing CVP and therefore venous outflow resistance, L-CRA may reduce the generalised vascular hypoperfusion occurring in those without anastomosis. Recent investigations with optical coherence tomography angiography have suggested that the deep capillary macular plexus (DCP), which has a lower perfusion pressure than the superficial plexus and drains predominantly into the retinal venous system, may be more susceptible to stagnation and hypoxic damage from raised CVP. ${ }^{17}$ It is therefore possible that persistently elevated CVP will, through backpressure via the DCP, increase the risk of progressive hypoxic macular damage and oedema.

As there remains considerable controversy concerning the nature and location of the obstruction to venous outflow, direct resolution of this appears currently 


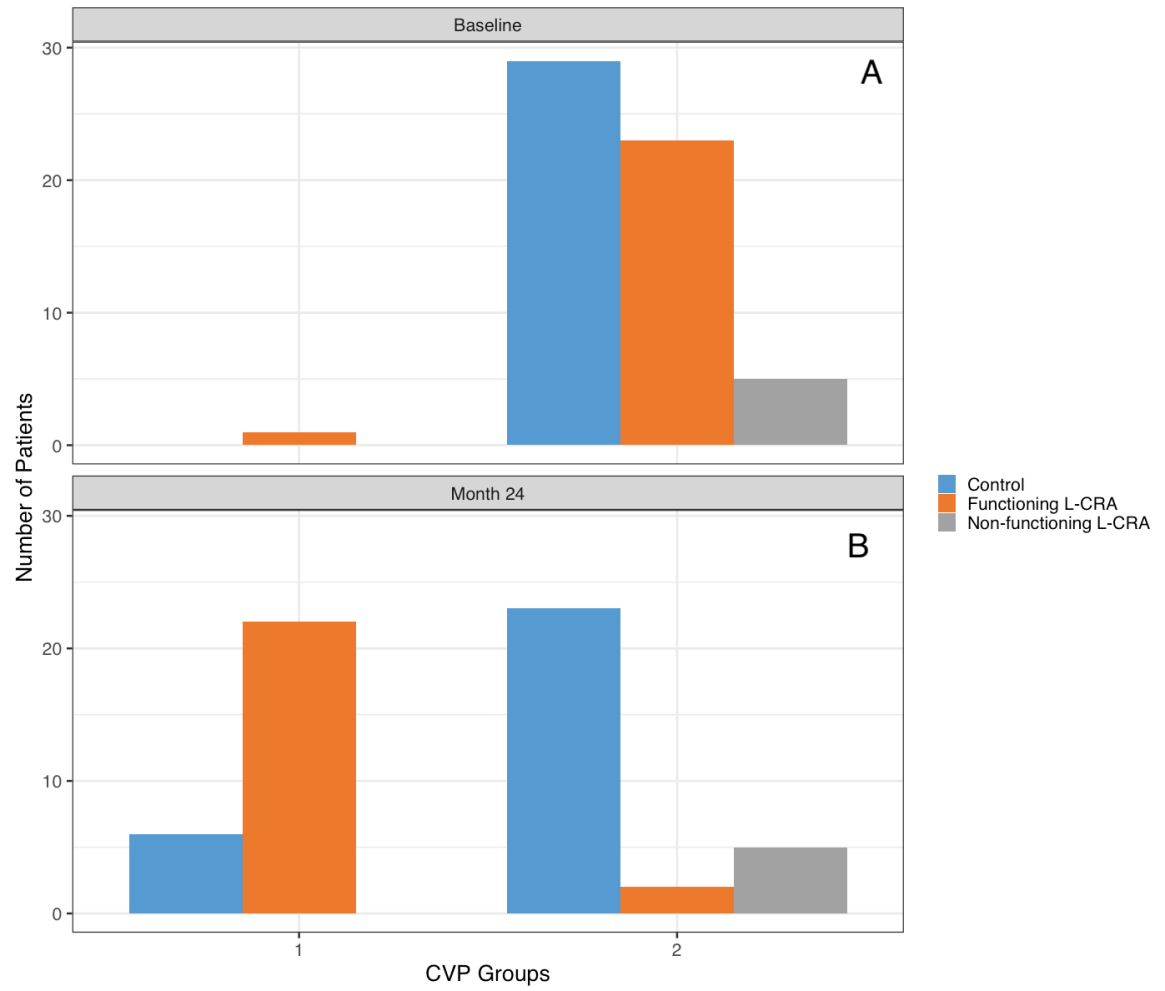

Figure 4 CVP at (A) baseline and (B) 24 months for the control, non-functioning L-CRA and functioning L-CRA groups. CVP is divided into two groups. Group 1 includes those with CVP less than the central retinal artery diastolic ('low CVP') pressure, and group 2 includes those with CVP equal to this or above ('high CVP'). CVP, central venous pressure; L-CRA, laser chorioretinal anastomosis.

impractical. ${ }^{18} 19$ The only option to address the elevated CVP would be to bypass the site of the obstruction and this is achievable as an outpatient procedure with the L-CRA, where an obstructed retinal vein is anastomosed with an unobstructed choroidal vein. ${ }^{7-9}$ The success rate of anastomosis creation in the original study was $82.8 \%$ and the complications of the procedure are manageable provided there is close follow-up and prompt intervention if required. ${ }^{720}$ This study has shown that the creation of a successful L-CRA can significantly reduce the injection load and improve BCVA outcomes presumably by lowering the CVP and thus addressing a critical component of CRVO-associated macular oedema. The treatment burden for patients with CRVO with conventional treatments remains high, and in many patients may persist for years. ${ }^{321}$ For those who developed a functional L-CRA, the mean number of injections for the second year was 0.9 compared with 4.6 for the control group, with no significant difference in CST between the groups. There was no significant difference identified between the control group and the group with a non-functioning L-CRA for injection loads, CST or BCVA outcomes. While the numbers in the non-functioning L-CRA group are small, it does appear that this group was not adversely affected compared with conventional treatment for their CRVO outcomes. As the functional L-CRA group had a significant improvement in BCVA over the 2-year follow-up despite the similar CST results to the control group, this would imply that addressing the component of the macular oedema and cytokine dysfunction contributed to by the elevated CVP has a beneficial effect not only on the requirements for intravitreal therapy but also on the visual acuity outcomes.

While visual acuity outcomes for CRVO-associated macular oedema have been impressive in RCTs, which led to the widespread use of VEGF antagonists for this indication, the results in real world-type studies have been less encouraging. Patients in these studies, which more accurately reflect the results being achieved in clinical practice, typically receive fewer injections and have poorer visual results than those in RCTs. Reasons include larger numbers of missed appointments and patients being lost to follow-up. ${ }^{21-24}$

The creation of a successful L-CRA can significantly reduce injection loads and improve visual outcomes, presumably by lowering the CVP, thereby addressing a critical component of CRVO-associated macular oedema. With conventional therapy, the treatment burden for patients with CRVO remains high and may persist for years, with high dropout rates in real-world studies. ${ }^{25}{ }^{26}$ Improving the outcomes for patients with CRVO will require ongoing efforts to address both the causal pathology as well as the cytokine dysregulation.

Contributors The original concept and design of the study were done by ILM, as were all procedures. Data collection was performed by LAS. Statistical analysis was performed by PS. Critical review of the manuscript, safety monitoring and drafting of the manuscript were done by all authors. 
Funding The ranibizumab used in this study was supplied by Novartis, Sydney, Australia. The sponsor of the drug had no role in the design or conduct of this research. The Centre for Eye Research Australia receives Operational Infrastructure Support from the Victorian Government. PS and FC are supported by Australian National Health and Medical Research Council Fellowships (MRF1142962:FKC).

Competing interests ILM is a board member of Novartis and Bayer (Switzerland). FC has received research funding from Novartis and has been a board member of Allergan, Alcon and Novartis.

Patient consent for publication Not required.

Ethics approval Institutional ethics committee approval was obtained from the Sir Charles Gairdner Hospital, and the study was performed according to the Declaration of Helsinki.

Provenance and peer review Not commissioned; internally peer reviewed.

Supplemental material This content has been supplied by the author(s). It has not been vetted by BMJ Publishing Group Limited (BMJ) and may not have been peer-reviewed. Any opinions or recommendations discussed are solely those of the author(s) and are not endorsed by BMJ. BMJ disclaims all liability and responsibility arising from any reliance placed on the content. Where the content includes any translated material, BMJ does not warrant the accuracy and reliability of the translations (including but not limited to local regulations, clinical guidelines, terminology, drug names and drug dosages), and is not responsible for any error and/or omissions arising from translation and adaptation or otherwise.

Open access This is an open access article distributed in accordance with the Creative Commons Attribution Non Commercial (CC BY-NC 4.0) license, which permits others to distribute, remix, adapt, build upon this work non-commercially, and license their derivative works on different terms, provided the original work is properly cited, appropriate credit is given, any changes made indicated, and the use is non-commercial. See: http://creativecommons.org/licenses/by-nc/4.0/.

ORCID iD

Ian L McAllister http://orcid.org/0000-0003-3262-0821

\section{REFERENCES}

1 Brown DM, Campochiaro PA, Singh RP, et al. Ranibizumab for macular edema following central retinal vein occlusion: six-month primary end point results of a phase III study. Ophthalmology 2010;117:1124-33.

2 Campochiaro PA, Brown DM, Awh CC, et al. Sustained benefits from ranibizumab for macular edema following central retinal vein occlusion: twelve-month outcomes of a phase III study. Ophthalmology 2011;118:2041-9.

3 Heier JS, Campochiaro PA, Yau L, et al. Ranibizumab for macular edema due to retinal vein occlusions: long-term follow-up in the horizon trial. Ophthalmology 2012;119:802-9.

4 Heier JS, Clark WL, Boyer DS, et al. Intravitreal aflibercept injection for macular edema due to central retinal vein occlusion: two-year results from the COPERNICUS study. Ophthalmology 2014; 121:1414-20.

5 Fekrat S, Shea AM, Hammill BG, et al. Resource use and costs of branch and central retinal vein occlusion in the elderly. Curr Med Res Opin 2010;26:223-30

6 Suñer IJ, Margolis J, Ruiz K, et al. Direct medical costs and resource use for treating central and branch retinal vein occlusion in commercially insured working-age and Medicare populations. Retina 2014:34:2250-8.

7 McAllister IL, Smithies LA, Chen FK, et al. Two-Year efficacy of ranibizumab plus laser-induced chorioretinal anastomosis vs ranibizumab monotherapy for central retinal vein occlusion: a randomized clinical trial. JAMA Ophthalmol 2018:136:1391-7.

8 McAllister IL, Gillies ME, Smithies LA, et al. The central retinal vein bypass study: a trial of laser-induced chorioretinal venous anastomosis for central retinal vein occlusion. Ophthalmology 2010;117:954-65.

9 McAllister IL, Smithies LA, Previn V. Technique of laser chorioretinal anastomosis creation in central retinal vein occlusion and success rate with a new photocoagulator system. Retina 2016;36:1971-8.

10 McAllister IL, Tan MH, Smithies LA, et al. The effect of central retinal venous pressure in patients with central retinal vein occlusion and a high mean area of nonperfusion. Ophthalmology 2014; 121:2228-36.

11 Jonas JB. Ophthalmodynamometric assessment of the central retinal vein collapse pressure in eyes with retinal vein stasis or occlusion. Graefes Arch Clin Exp Ophthalmol 2003;241:367-70.

12 Jonas JB, Harder B. Ophthalmodynamometric differences between ischemic vs nonischemic retinal vein occlusion. Am J Ophthalmol 2007;143:112-6.

13 Krohne TU, Liu Z, Holz FG, et al. Intraocular pharmacokinetics of ranibizumab following a single intravitreal injection in humans. Am J Ophthalmol 2012;154:682-6.

14 Ozaki H, Hayashi $\mathrm{H}$, Vinores SA, et al. Intravitreal sustained release of VEGF causes retinal neovascularization in rabbits and breakdown of the blood-retinal barrier in rabbits and primates. Exp Eye Res 1997:64:505-17.

15 McAllister IL, Vijayasekaran S, Chen SD, et al. Effect of triamcinolone acetonide on vascular endothelial growth factor and occludin levels in branch retinal vein occlusion. Am J Ophthalmol 2009;147:838-46.

16 Larsen M, Waldstein SM, Priglinger S, et al. Sustained Benefits from Ranibizumab for Central Retinal Vein Occlusion with Macular Edema: 24-Month Results of the CRYSTAL Study. Ophthalmol Retina 2018;2:134-42.

17 Spaide RF. Volume-Rendered optical coherence tomography of retinal vein occlusion pilot study. Am J Ophthalmol 2016;165:133-44.

18 Beaumont PE, Kang HK. Pattern of vascular nonperfusion in retinal venous occlusions occurring within the optic nerve with and without optic nerve head swelling. Arch Ophthalmo/ 2000;118:1357-63.

19 Hayreh SS. Prevalent misconceptions about acute retinal vascular occlusive disorders. Prog Retin Eye Res 2005;24:493-519.

20 McAllister IL, Gillies ME, Smithies LA, et al. Factors promoting success and influencing complications in laser-induced central vein bypass. Ophthalmology 2012;119:2579-86.

21 Callizo J, Ziemssen F, Bertelmann T, et al. Real-World data: ranibizumab treatment for retinal vein occlusion in the ocean study. Clin Ophthalmol 2019;13:2167-79.

22 Kiss S, Liu Y, Brown J, et al. Clinical utilization of anti-vascular endothelial growth-factor agents and patient monitoring in retinal vein occlusion and diabetic macular edema. Clin Ophthalmol 2014;8:1611-21.

23 Jumper JM, Dugel PU, Chen S, et al. Anti-VEGF treatment of macular edema associated with retinal vein occlusion: patterns of use and effectiveness in clinical practice (ECHO study report 2). Clin Ophthalmol 2018:12:621-9.

24 Wecker T, Ehlken C, Bühler A, et al. Five-Year visual acuity outcomes and injection patterns in patients with pro-re-nata treatments for AMD, DME, RVO and myopic CNV. Br J Ophthalmol 2017;101:353-9.

25 Gao X, Obeid A, Adam MK, et al. Loss to follow-up in patients with retinal vein occlusion undergoing intravitreal anti-VEGF injections. Ophthalmic Surg Lasers Imaging Retina 2019;50:159-66.

26 Campochiaro PA, Sophie R, Pearlman J, et al. Long-Term outcomes in patients with retinal vein occlusion treated with ranibizumab: the RETAIN study. Ophthalmology 2014;121:209-19. 